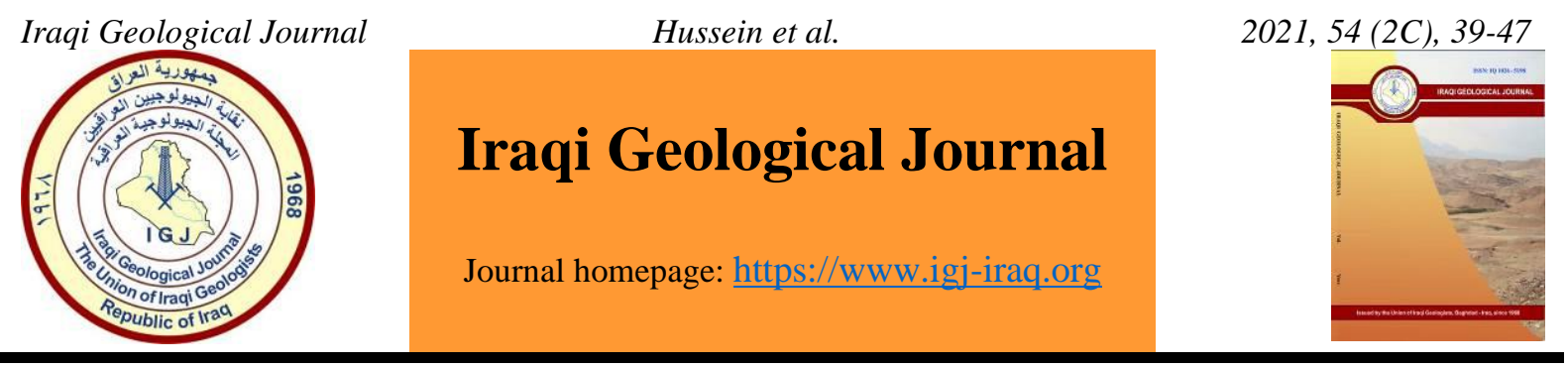

\title{
Study of Petrophysical Properties of the Yamama Formation in Siba Oilfield
}

\author{
Hussein Y. Ali ${ }^{1}$ *, Ghanim M. Farman ${ }^{1}$ and Mohammed H. Hafiz ${ }^{2}$ \\ 1 Department of Petroleum Engineering, College of Engineering, University of Baghdad, Baghdad, Iraq \\ 2 Basrah University for Oil and Gas, Basrah, Iraq \\ * Correspondence: h.ali1908m@coeng.uobaghdad.edu.iq
}

Received: 6 June 2021; Accepted: 6 July 2021; Published: 30 September 2021

\begin{abstract}
Evaluating a reservoir to looking for hydrocarbon bearing zones, by determining the petrophysical properties in two wells of the Yamama Formation in Siba field using Schlumberger Techlog software. Three porosity logs were used to identify lithology using MN and MID cross plots. Shale volume were calculated using gamma ray $\log$ in well Sb-6ST1 and corrected gamma ray in well Sb-5B. Sonic log was used to calculate porosity in bad hole intervals while from density log at in-gauge intervals. Moreover, water saturation was computed from the modified Simandoux equation and compared to the Archie equation. Finally, Permeability was estimated using a flow zone indicator. The results show that the Yamama Formation is found to be mainly limestone that confirmed by cuttings description and this lithology intermixed with some dolomite, in addition to gas and secondary porosity effects. Generally, the formation is considered clean due to the low shale volume in both wells with the elimination of the uranium effect in well Sb-5B. The calculated porosity was validated by core porosity in YC and YD units. Modified Simandoux gives a better estimation than the Archie equation since it takes into account the conductive of matrix in addition to the fluid conductivity. Five equations were obtained from porosity permeability relationship of core data based on five hydraulic flow units reorganized from the cross plot of reservoir quality index against normalized porosity index. The overall interpretation showed that $\mathrm{YC}$ and YD units are the best quality hydrocarbon units in the Yamama Formation, while YA came in the second importance and has properties better than YB. Moreover, YE and YFG are poor units due to high water saturation.
\end{abstract}

Keywords: Petrophysical properties; Shale volume; Porosity; Permeability; Water saturation

\section{Introduction}

The evaluation of the petrophysical properties is considered an essential part when describing the features of the hydrocarbon reservoirs where the interaction, as well as the characterization in the reservoirs and non-reservoir rocks between the rock and fluids, helps to determine various properties such as porosity which represents the network character of the pores, in addition to permeability and saturation that describes the path of the fluid and its distribution in the network, respectively (Cannon, 2016). Generally, as demonstrated byKennedy (2015). There are two sources of data when dealing with these properties, instrumental methods that measure the properties against depth which called logs and the actual samples that almost represent the formation that we are dealing with such as cuttings and

DOI: 10.46717/igj.54.2C.4Ms-2021-09-23 
cores (Idan et al., 2020). Cross plots are common methods to exhibit effect of combinations of logs react to porosity and lithology and they give a visual vision into the type of lithology mixtures (Liu, 2017) .The quantitative evaluation of a hydrocarbon units in a reservoir requires a correct prediction of the shale volume which causes a blockage to the pore space and reduce the amount of permeability and as a result reduce the reservoir quality (Poupon and Gaymard, 1969). Many types of well logs can be used to calculate porosity as indirect method which requires the use of various factors that represent a property of the formation and the fluid within(Jenkins, 1960). One of the fundamental task is the calculation of water saturation which has the impact on fluid distribution in the reservoir so as a result the calculations of hydrocarbon in place and due to the degree of uncertainty that combined with several measurement required, it become more difficult to compute rather than porosity (Cannon, 2016). For petroleum engineers, Permeability is a primary input and an important key in reservoir management as well as in development for example when choosing the optimum production rate for the field and water injection patterns(Ahmed et al., 1991). Hydraulic flow unit used to split the reservoir into zones and each flow unit can be identified by applying a flow zone indicator (FZI) which used to calculate permeability where the core data is not available (Amaefule et al., 1993).

\section{Study Area}

In 1969, Siba gas field was discovered in southeast of Basra by ELF Iraq company. The field is expected to extend through Shatt Al-Arab to Iran territory, but the largest part is within the Iraqi region as shown in Fig. 1. The length of Siba field around $25 \mathrm{~km}$, while $6 \mathrm{~km}$ wide where the structure is anticline and comprises of two domes with a saddle between them according to the seismic studies (Kadhim, 2015; Odeh and Ali, 2021).

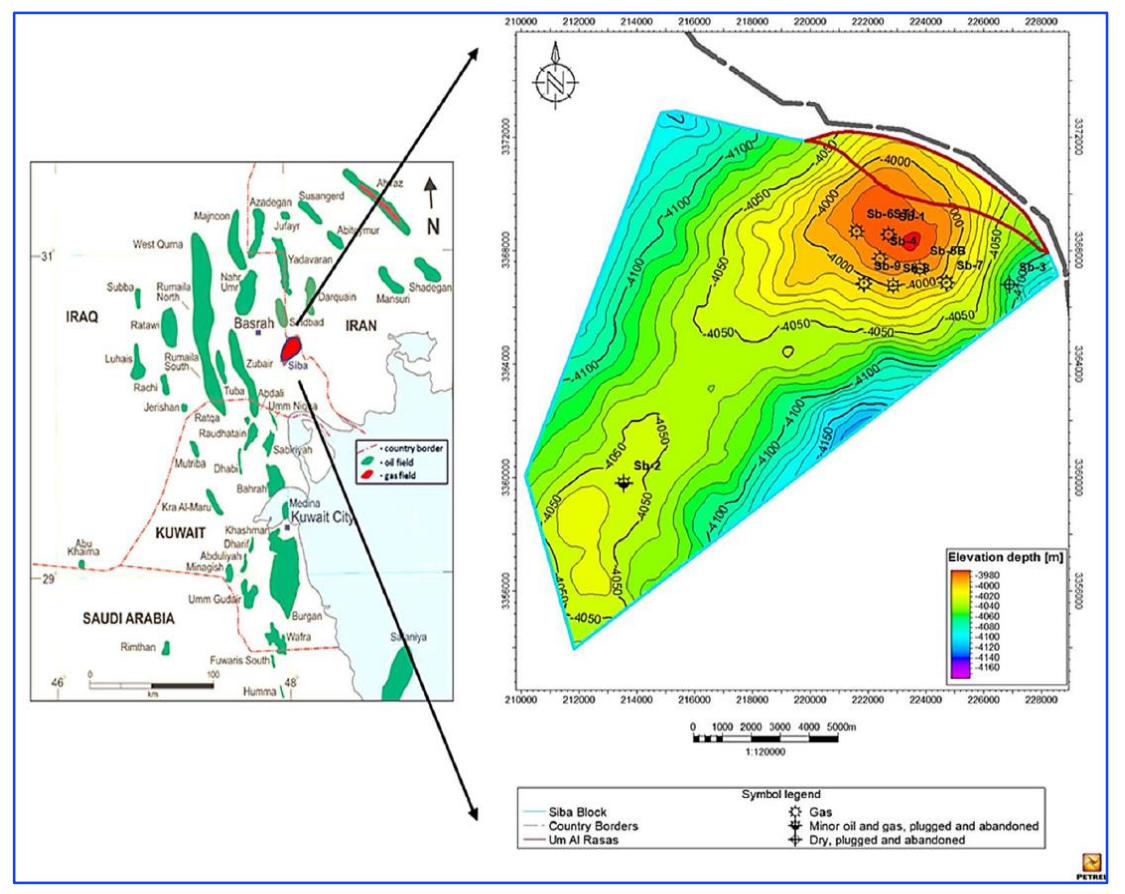

Fig.1. Location map of Siba Field (Aljazaeri and Handhal, 2020)

\section{Materials and Methods}

This research includes the analysis of petrophysical properties in two wells (Sb-6ST1and Sb-5B) of the Yamama Formation based on a conventional open hole log in Siba field. The Yamama Formation is divided into six units and these are YA, YB, YC (YC_U, YC_L), YD (YD, YD_1, YD_2), YE and YFG which separated by barriers. Most of logs are available in digital format (LAS) which has been 
imported directly into Schlumberger Techlog software (version 2017.1) while others as a field print thus by using Neutron Log (version 2015.04) a digitization was performed to export these logs into LAS file. Moreover, 103 core plugs with porosity-permeability reading are available in well Sb-6ST1 at YC and YD units. Quality control was applied to all logging measurements through two steps since the quality of the input determines the accuracy of the output. In the first place, the depth of all logs in each well were examined for the matching purposes and this was done by taking the gamma ray as a reference $\log$. Moreover, environment correction has been used to remove the effect of the borehole condition to those logs that are not corrected by the service company as well as when there is a missing correction in the already corrected curves. The methods in this study are divided into five parts as shown in Fig. 2 .

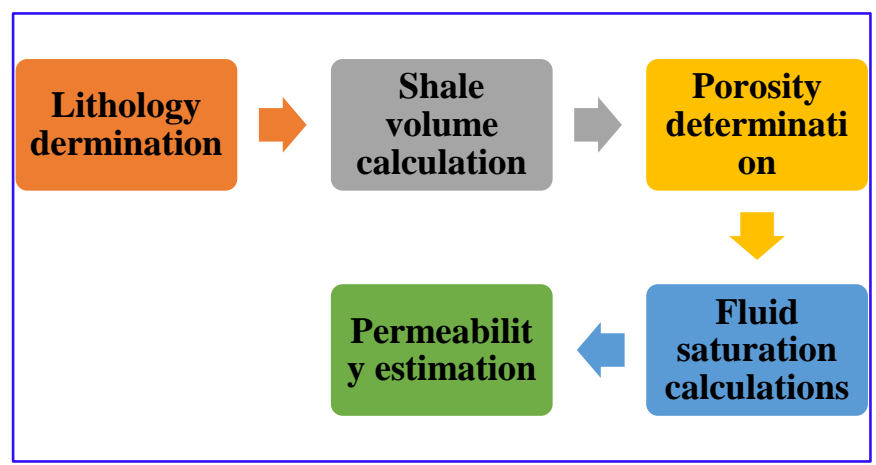

Fig.2. Flow diagram of methodology

\section{Results}

The main important results of this research are listed below.

\subsection{Lithology Determination}

Mineral identification (MN ) and matrix identification (MID) cross plots were used in this study and they are determined from the following equations (Dewan, 1978) :

$$
\begin{aligned}
& M=((\Delta t f-\Delta t \log ) /(\rho b-\rho f)) * 0.01 \\
& N=(\varnothing n f-\varnothing n \log ) /(\rho b-\rho f) \\
& \rho m a a=(\rho b-\varnothing t a * \rho f) /(1-\varnothing t a) \\
& \Delta t m a a=\left(\Delta t \log -\Delta t f^{*} \varnothing t a\right) /(1-\varnothing t a)
\end{aligned}
$$

Where $\Delta \mathrm{tlog}, \Delta \mathrm{tf}$ and $\Delta \mathrm{tmaa}$ represent sonic log, sonic log reading for pore fluid and apparent matrix travel time, respectively. While $\rho b$, $\rho$ f and $\rho$ maa are density $\log$, density log reading for pore fluid and apparent matrix density, respectively. Moreover, $\emptyset$ nlog, $\emptyset$ nf and $\emptyset$ ta are neutron log, neutron $\log$ reading for pore fluid as well as apparent total porosity (Fig. 3 and Fig. 4).

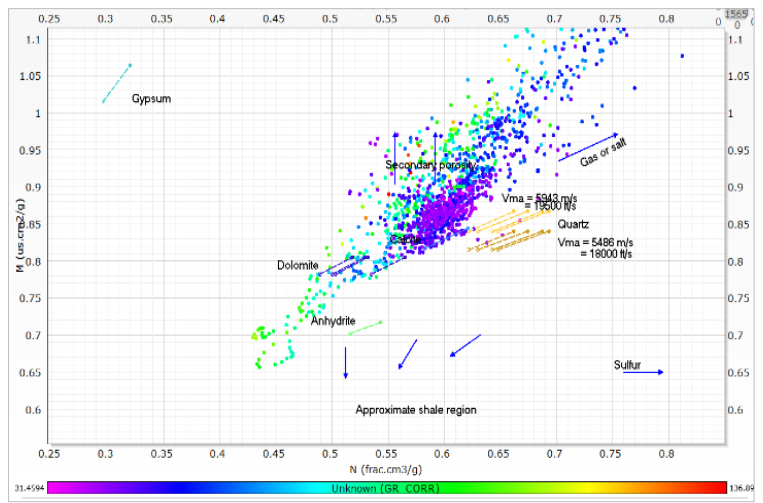

(a)

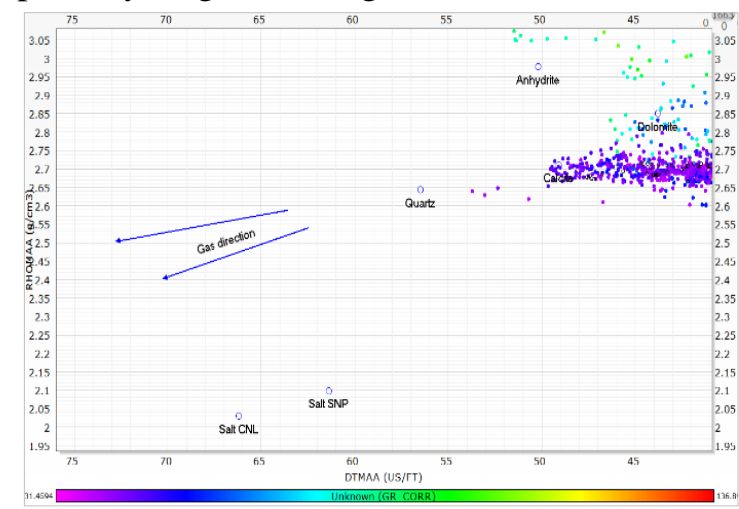

(b)

Fig.3. Lithology determination for well Sb-6ST1 (a) MN plot (b) MID plot 


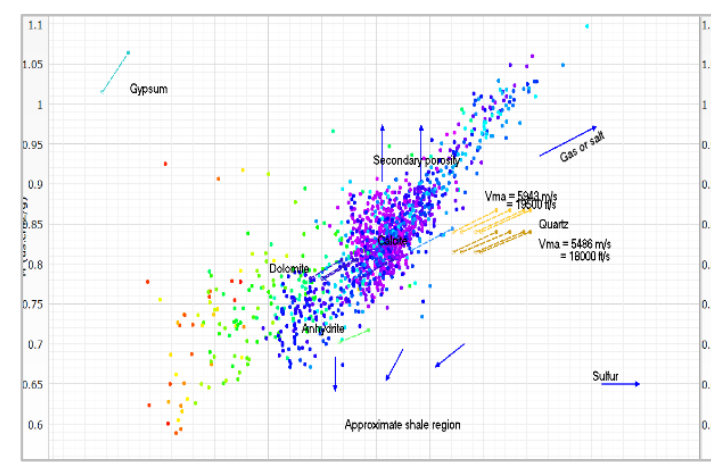

(a)

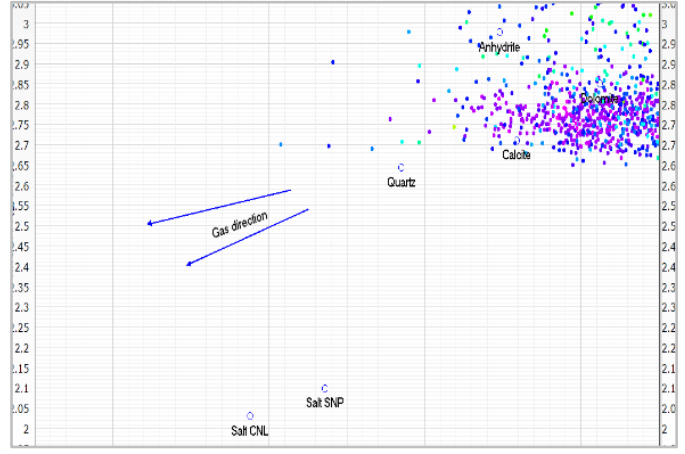

(b)

Fig.4. Lithology determination for well Sb-5B (a) MN plot (b) MID plot

\subsection{Shale Volume Calculation}

The older rocks equation has been used to calculate shale volume (Vsh) from gamma ray (GR) as well as the corrected gamma ray (CGR) (Liu, 2017):

$$
\begin{aligned}
& I s h=(\text { GRlog }- \text { GRmin }) /(\text { GRmax }- \text { GRmin }) \\
& I s h=(\text { CGRlog }- \text { CGRmin }) /(\text { CGRmax }- \text { CGRmin }) \\
& V s h=0.33 *\left(2^{(2 * I s h)}-1\right)
\end{aligned}
$$

Where Ish is the index of shaliness while the suffixes (min) and (max) represent the clean and shale readings, respectively for each log. Equation 5 was used in well Sb-6ST1 while equation 6 used in well $\mathrm{Sb}-5 \mathrm{~B}$ due to the availability of the corrected gamma ray (CGR) in this well as illustrated in Fig.5.

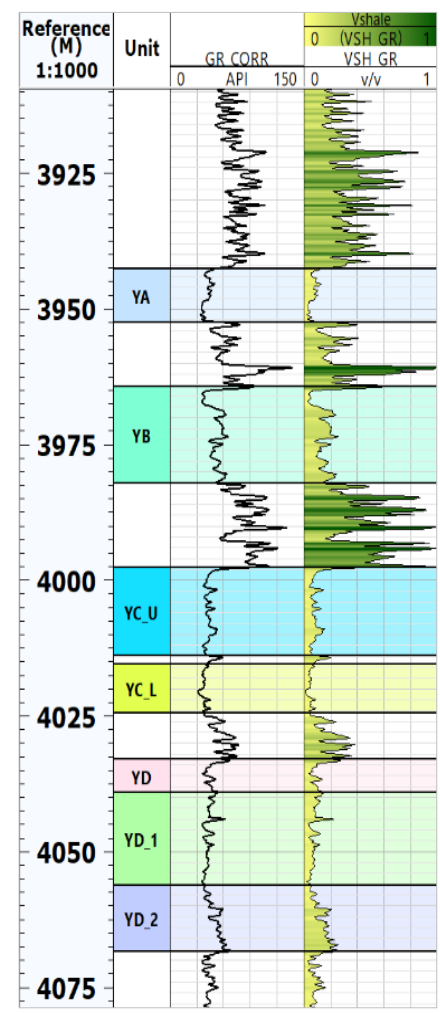

(a)

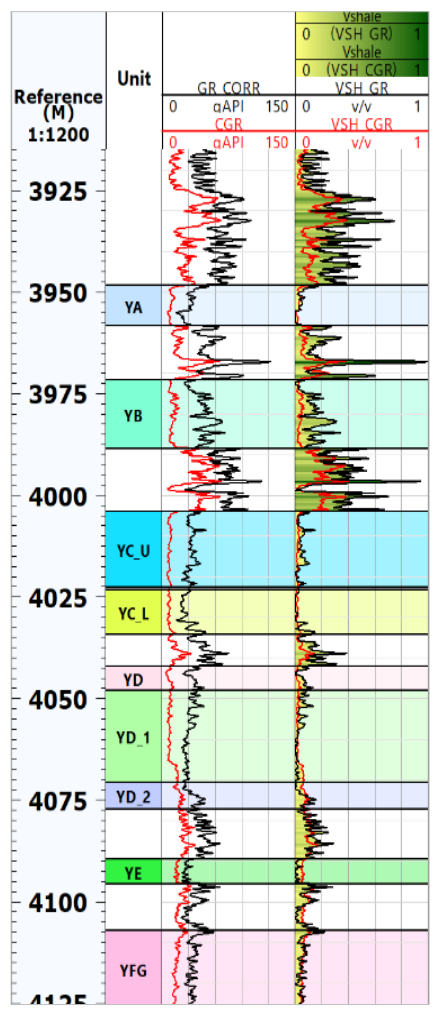

(b)

Fig.5. Shale volume calculation (a) Well Sb-6ST1 (b) Well Sb-5B 


\subsection{Porosity Determination}

This property was calculated from density log at in-gauge intervals while from sonic log in bad hole intervals. Equation 8 has been used to calculate total porosity ( $\varnothing \mathrm{d})$ from density log (Liu, 2017), while equation 9 used to calculate total porosity $(\varnothing \mathrm{s})$ from sonic log:

$$
\begin{aligned}
& \emptyset d=(\rho m a a-\rho b) /(\rho m a a-\rho f) \\
& \emptyset_{s}=(\Delta t-\Delta t m a a) /(\Delta t f-\Delta t m a a)
\end{aligned}
$$

The effective porosity (Øe) which represents our target in this step, was calculated from the following equation(Liu, 2017) :

$$
\varnothing e=\varnothing t-\emptyset_{s}{ }^{*} V s h
$$

Where $\emptyset \mathrm{t}$ is the total porosity that calculated from equations 8 and 9 while $\emptyset$ sh represents the shale porosity. The calculated results presented in Fig. 6 in track 3 and 4 for the study wells.

\subsection{Fluid Saturation Calculations}

Modified Simandoux method has been used to calculate water saturation in Yamama Formation for the true zone (Sw) as well as the invaded zone(Sxo) (Kumar, 2010) :

$$
\begin{aligned}
& S w=\left((-V s h / R s h) \pm\left((V s h / R s h)^{2}+\left(4 \emptyset^{n} /\left(a^{*} R w^{*} R t(1-V s h)\right)\right)\right)^{0.5}\right) /\left(2 \emptyset^{n} /\left(a^{*} R w(1-V s h)\right)\right) \\
& S x o=\left((-V s h / R s h) \pm\left((V s h / R s h)^{2}+\left(4 \emptyset^{n} /\left(a^{*} R m f * R x o(1-V s h)\right)\right)\right)^{0.5}\right) /\left(2 \emptyset^{n} /\left(a^{*} R m f(1-V s h)\right)\right)
\end{aligned}
$$

Where $(\mathrm{m})$ and (a) are cementation exponent and tortuosity factor, respectively. While, (Rsh), (Rt), (Rxo) are shale, deep and shallow resistivities, respectively. Moreover, (Rw)and (Rmf) are formation water and mud filtrate resistivities, respectively. Similarly the hydrocarbon saturation $(\mathrm{SH})$ and the moveable hydrocarbon saturation $(\mathrm{SHm})$ can be determined from the following equations, respectively (Bateman, 1987):

$S H=1-S w$

$\mathrm{SH} m=\mathrm{Sxo}-\mathrm{Sw}$

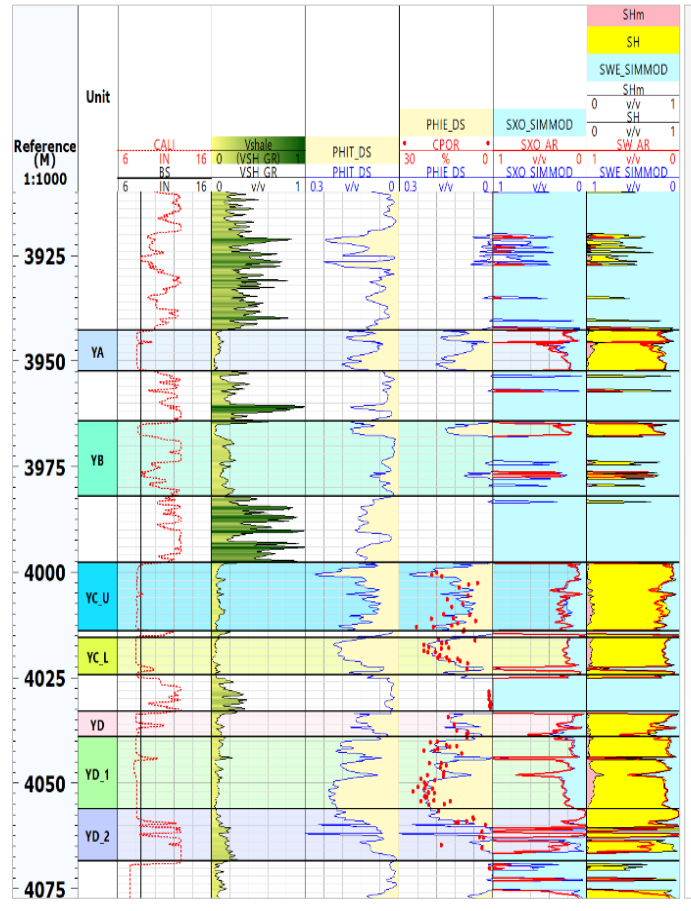

(a)

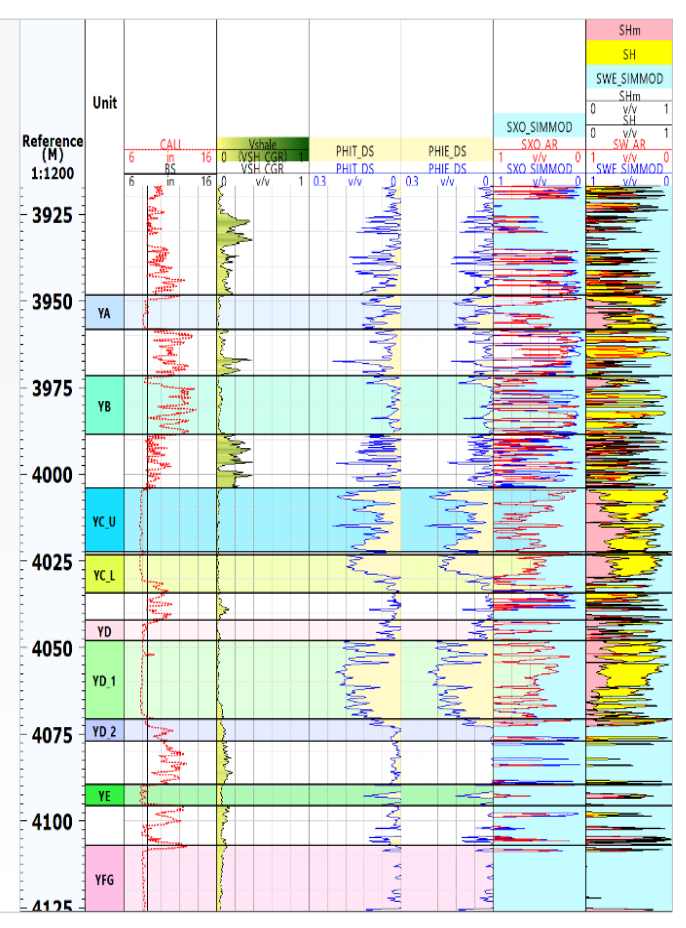

(b)

Fig.6. Techlog software interpretation (a) Well Sb-6ST1 (b) Well Sb-5B 


\subsection{Permeability Estimation}

As presented by Amaefule et al. (1993), permeability could estimate from a flow zone indicator (FZI) (Fig. 7) which is a unique parameter for each hydraulic unit that obtained from the intercept with normalized porosity index $\left(\varnothing_{\mathrm{z}}\right)=1$ of the unit slop line which resulting from plotting on log log graph a reservoir quality index (RQI) against normalized porosity index $(\varnothing \mathrm{z})$ using the following equations :

$$
\begin{aligned}
& R Q I=0.0314 *(K / \varnothing e)^{0.5} \\
& \varnothing z=\varnothing e /(1-\emptyset e) \\
& F Z I=R Q I / \varnothing z \\
& K=104 I^{*} F Z I^{2} *\left(\varnothing e^{3} /(1-\varnothing e)^{2}\right)
\end{aligned}
$$

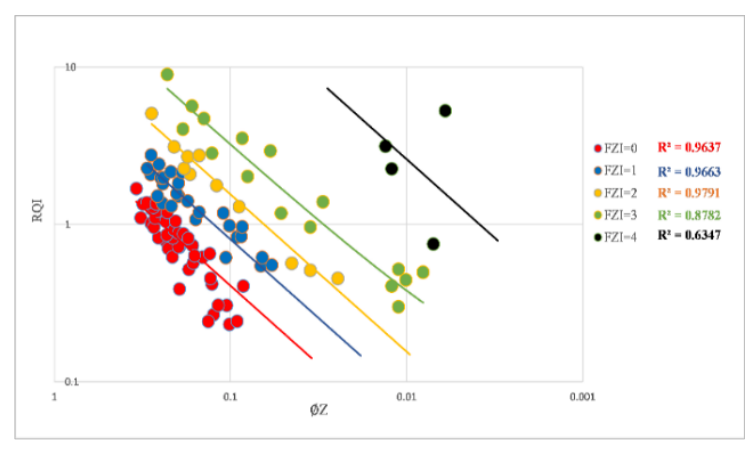

(a)

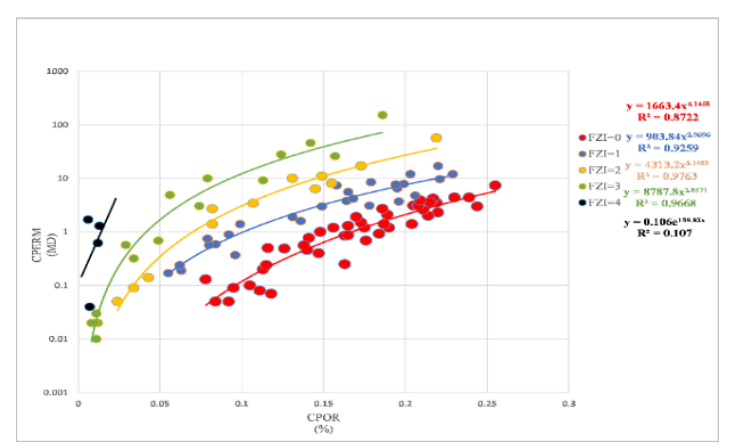

(b)

Fig.7. Permeability estimation using FZI in well Sb-6ST1 (a) Cross plot RQI vs $\emptyset \mathrm{z}$ (b) Cross plot CPERM vs

$$
\text { CPOR }
$$

Also, the average results of this research are shown in Table 1 for the study wells

Table 1. The results of petrophysical properties as average values

\begin{tabular}{ccccccc}
\hline Well & Unit & & Shale volume & Effective porosity & Water saturation & Permeability \\
\hline \multirow{6}{*}{ Sb-6ST1 } & YA & & 0.06856647 & 0.1109399 & 0.1828112 & 1.954033 \\
& YB & & 0.1592261 & 0.02590363 & 0.7738075 & 0.9753333 \\
& & YC_U & 0.08912486 & 0.1163334 & 0.1641755 & 2.558669 \\
& & YC_L & 0.04670067 & 0.1469513 & 0.1955181 & 3.999 \\
& YD & 0.1047013 & 0.08472179 & 0.2513181 & 1.140112 \\
& & YD_1 & 0.07862037 & 0.1653788 & 0.1767446 & 5.557951 \\
& YD_2 & 0.1380011 & 0.07523199 & 0.3222052 & 3.047796 \\
& & 0.02707918 & 0.06724341 & 0.3167872 & 0.601977 \\
& YB & & 0.03455491 & 0.02017812 & 0.5808703 & 0.0812901 \\
& & YC_U & 0.01961859 & 0.1046103 & 0.2987338 & 1.947286 \\
& & YC_L & 0.01824144 & 0.09198716 & 0.4434223 & 1.826853 \\
& & YD & 0.01929426 & 0.03683616 & 0.557162 & 0.1219133 \\
& YD & YD_1 & 0.02656616 & 0.1455032 & 0.3806748 & 3.595069 \\
& & YD_2 & 0.07067095 & 0.02807376 & 0.6717144 & 0.3222849 \\
& YE & & 0.05715296 & 0.02243724 & 0.8375436 & 0.3721777 \\
& YFG & & 0.05655548 & 0.008641596 & 0.9554509 & 0.1240287 \\
\hline
\end{tabular}




\section{Discussion}

limestone is one of the most reservoir rocks in oil and gas industry(Serra, 2007). Determination of the lithology can be recognized by certain methods and one of them from well logs which gives a reliable result. MN and MID cross plots were used in this study which combining three porosity logs instead of two to eliminate the variation effect of porosity so by using these plots the researcher could identify the effect of gas and secondary porosity as well as a better estimation of lithology. In the present study we did not use neutron density cross plot which is the most common in lithology determination, for the reason that this plot is used only two porosity logs and these logs are effect by many conditions as well as it contains three matrices' lines only, beside that it's may show a wrong result in special cases for example when the formation is consist of sandstone and dolomite, the points may lie on limestone line. Fig. 3 and Fig. 4 indicated that the main lithology of Yamama in this field is limestone (calcite) with some dolomite and there is an observation of secondary porosity and gas effect since the points shifted towards their directions. Cuttings from of the two wells are also supported findings and show evidence of limestone.

In Techlog software, there are more than eight methods available to calculate shale volume. In the present study, we preferred gamma ray over other methods since there are many parameters effect on other logs readings for example the bad hole on density log and they were used in special cases or where gamma ray is not available. Gamma ray is a tough log and its designed for this purpose and its measure the natural radioactive elements of the formation which is found in shale while the limestone which represents a reservoir rock has low radioactivity as a result low gamma ray reading (Liu, 2017).Another form of gamma ray log, is the spectral gamma ray which separate the total gamma ray reading into their components, in other words its measure the concentration of potassium, thorium and uranium individually (Heflin et al., 1980).In present study we also used the corrected gamma ray (CGR) which is only available in well Sb-5B, this type consist of potassium and thorium only which represent shale only, since the high existence of uranium in the organic material give an overestimation results and thus underestimate the effective porosity (Soto et al., 2010). The results in Fig. 5 show that the Yamama Formation is clean where the volume of shale calculated by CGR is slightly less than the calculated by GR in well Sb-5B because the contribution of uranium element in the measured volume by GR. The reason behind using sonic log in the washout intervals due to the bad hole condition putting less confidence in the density log measurement and reduce the reading so when there is a high washout in the borehole as our case, the porosity will be overestimated (Ellis, 2003) .Moreover, the results in well Sb-6ST1 were validated by using core porosity (CPOR) in YC and YD units after shifting the core depth to the log depth as shown in Fig. 6 (a) where it's clear that these units in both wells has the highest porosity.

To support our findings in water saturation, Archie which is a common equation was tested also to calculate water saturation and it obvious that both equations gave the same results in the clean zones (Fig. 6), in other words where the shale volume is low but in high shale intervals, there is a minor difference between them in which Archie equation shows approximately higher values than the mentioned equation. Archie equation (Archie, 1941) applicable in clean formation only, he assumed that the conductive path from the fluid only, in other words the matrix is not conductive so he neglected the conductivity of shale (Peeters, 2011) which could be related to clay minerals and the conductivity of bound water and as result additional reduction in deep resistivity, that's why we got slightly high values of water saturation. Generally, many water saturation equations will almost give the same results especially in the clean intervals but we chose modified Simandoux equation since this method is recommended by French Institute of Petroleum and its offer a best way to compute water saturation (Fertl and Hammack, 1972). 
For permeability, at the beginning, we tried to use porosity-permeability relationship of core data to develop an equation to estimate permeability but due to the heterogeneity we got low values of $\mathrm{R}^{2}$ so we moved directly to the second option through using flow zone indicator (FZI) method. Fig 7 (a) shows the existence of five flow units, samples of same FZI value have similar features of pore throat and therefore, the same flow unit. Accordingly, the porosity-permeability data were classified based on the FZI values as shown in Fig. 7 (b) and a high value of $\mathrm{R}^{2}$ were obtained except for FZI=4 which contains only 4 samples out of 103 , therefore permeability can be estimated precisely from the curve equation for each flow unit.

\section{Conclusions}

A good insight of lithology was obtained by using MN and MID cross plots, these plots show the lithology of Yamama consists mainly of limestone which is supported by cutting description in addition to some dolomite with secondary porosity indication and gas effect. By using gamma ray log, shale volume was calculated in well Sb-6ST1 while from the corrected gamma ray in well Sb-5B which represents the best choice to calculate the volume of shale due to the elimination of uranium that may be found in the reservoir rocks within the organic material and as a result overestimates the shale volume. Porosity was calculated from the combination of density log at in-gauge intervals and from the sonic $\log$ in bad hole intervals and this porosity were validated by core porosity. Modified Simandoux equation has been used to calculate water saturation in the selected wells since this equation considers the conductivity in the matrix in addition to fluid within, on the other hand Archie equation considered the conductive path in fluid only that's why this equation gave nearly high values of water saturation in high shale zones. Due to complex heterogeneity of limestone rocks, permeability was estimated by FZI method which develops five hydraulic flow units achieved from the cross plot of reservoir quality index with normalized porosity index and as a result the core data of porosity permeability were classified into five flow units and good $\mathrm{R}^{2}$ values were obtained $(0.8722,0.9259,0.9763$ and 0.9668$)$ except for FZI=4 where the value is (0.107). Generally, most of hydrocarbons are located in YC and YD units which represents the best units in Yamama Formation, with good hydrocarbons in YA in which the properties of this unit in well Sb-6ST1 better than in well Sb-5B. Finally, YE and YFG supposed to be water units rather than hydrocarbon units due to the existence of high-water saturation as well as there is a very weak to no hydrocarbon shows at the surface while drilling these units.

\section{Acknowledgements}

The authors are very grateful to the Editor in Chief Prof. Dr. Salih M. Awadh, the Secretary of Journal Mr. Samir R. Hijab. and the Technical Editors for their great efforts and valuable comments.

\section{References}

Ahmed, U., Crary, S. F., and Coates, G. R., 1991. Permeability estimation. The various sources and their interrelationships. Journal of Petroleum Technology, 43(5), 578-587.

Aljazaeri, M. Q. and Handhal, A. M., 2020. Modeling of thermal and burial histories for selected deep formations in the Middle-Jurassic to Lower Cretaceous in Siba Gas field, Southern Iraq. Modeling Earth Systems and Environment, 6 (2), 627-643.

Amaefule, J., Altunbay, M., Tiab, D., Kersey, D. and Keelan, D., 1993.Enhanced reservoir description: using core and $\log$ data to identify hydraulic (flow) units and predict permeability in uncored intervals/ wells. SPE Annual Technical Conference and Exhibition.Omega(c), 205-220.

Archie, G. E.,1941.The electrical resistivity $\log$ as an aid in determining some reservoir characteristics.SPE Reprint Series. (55), 9-16.

Bateman, R., 1987.Open-hole log analysis and formation evaluation.Marine and Petroleum Geology, 90-277, 647. 
Cannon, S., 2016. Petrophysics, a practical guide. $1^{\text {st }}$ ed .India: John Wiley and Sons, Inc..

Dewan, J., 1978. Essentials of Modern Open-Hole Log Interpretation. $1^{\text {st }}$ ed .USA: PennWell Corporation.

Ellis, D., 2003. Formation porosity estimation from density logs.Petrophysics. 44(5), pp. 306-316.

Fertl, W. and Hammack, G., 1972. A comparative look at water saturation computations in shly pay sands.

Heflin, D. and Nettleton, K. A., 1980. Formation evaluation utilizing gamma ray spectral analysis. SPE Rocky Mount in Regional Meeting. Casper, Wyoming. May 14-16.

Idan, R.M., Salih, A.L., Al-Khazraji, O.N. and Khudhair, M.H., 2020. Depositional environments, facies distribution, and porosity analysis of Yamama Formation in Majnoon oilfield. Sequence stratigraphic approach. The Iraqi Geological Journal, 53(1D), 38-52.

Jenkins, R. E., 1960. Accuracy of porosity determinations.SPWLA 1st Annual Logging Symposium, May.

Kadhim, A. K., 2015. Mathematical Modeling of Yamama Reservoir, Siba Field. Msc. thesis, University of Baghdad, Baghdad, Iraq.

Kennedy, M., 2015. Practical petrophysics. $1^{\text {st }}$ ed .USA: Elsevier, 62.

Kumar, K. C. H., 2010. On the Application of Simandoux and Indonesian Shaly Sand Resistivity Interpretation Models in Low and High Rw Regimes.8th Biennial International Conference and Exposition on Petroleum Geophysics, 11 .

Liu, H., 2017. Principles and Applications of Well Logging.Petroleum Industry Press and Springer.China.

Odeh, B.M. and Ali, K.K., 2021. Structural Interpretation of Yamama and Naokelekan Formations in Tuba Oil Field Using 2D Seismic Data. The Iraqi Geological Journal, 54(2B), 55-64.

Peeters, M., 2011. Review of existing shaly sand evaluation models and introduction of a new method based on dry clay parameters. SPWLA 52nd Annual Logging Symposium, 55(6), 543-553.

Poupon, A. and Gaymard, R., 1969. The Evaluation of clay content from logs.The American Mathematical Monthly. 76(5), 546-547.

Serra, O., 2007. Well Logging and Reservoir Evaluation.France:Editions Technips, 3, 250.

Soto, B. R., Arteaga, D., Martin, C. and Rodriguez, F., 2010. The correct shale-volume characterization increases hydrocarbon reserves: Case study of cretaceous formation, lake Maracaibo, Venezuela. SPE Latin American and Caribbean Petroleum Engineering Conference Proceedings, 1-181-189. 